\title{
Identification of early response to hypertonic dextrose prolotherapy markers in knee osteoarthritis patients by an inflammation-related cytokine array
}

\author{
Hsing-Chun Kuo ( $\sim$ guscsi@gmail.com ) \\ Chang Gung University of Science and Technology \\ Po-Jung Pan \\ National Yang Ming University Hospital \\ Jia-Chi Wang \\ Taipei Veterans General Hospital Su-Ao and Yuanshan Branch \\ Chih-Chun Tsai \\ Tamkang University
}

\section{Research article}

Keywords: osteoarthritis, knee OA, hypertonic dextrose prolotherapy, protein-expression profile, prognostic markers

Posted Date: June 1st, 2020

DOI: https://doi.org/10.21203/rs.3.rs-30677/v1

License: (9) (i) This work is licensed under a Creative Commons Attribution 4.0 International License. Read Full License 


\section{Abstract}

\section{BACKGROUND/AIM}

Osteoarthritis $(\mathrm{OA})$ is one of the most common forms of arthritis, and hypertonic dextrose prolotherapy has long been used clinically to treat knee OA. The aim of this study was to investigate the inflammation-related protein-expression profile characterizing the efficacy of the hypertonic dextrose prolotherapy in knee OA as prognostic markers.

\section{METHODS}

OA patients over the age of 65 were recruited for Western Ontario McMaster University Osteoarthritis (WOMAC) index, knee X ray evaluation and knee joint synovial fluid analysis before and after hypertonic dextrose prolotherapy. The expressions of inflammation-related factors were measured using a novel cytokine antibody array methodology. The cytokine levels were quantified by quantitative protein expression and analyzed by ELISA using the patients' knee-joint synovial fluid. The WOMAC Index and minimum joint space width prior to receiving the intra-articular injection and at 2-week intervals were compared.

\section{RESULTS}

12 patients who received OA intervention were enrolled and finally a clinical evaluation of 12 knee joints and knee synovial fluid samples were analyzed. In this study, after receiving hypertonic dextrose prolotherapy, the OA patients clearly demonstrated a significant improvement in WOMAC index and increasing tendency in the medial minimum joint space width after intervention. Meanwhile, we observed a significantly associated tendency between the high-glucose treatment of knee OA and the upregulation of MMP2, TIMP-1, EGF, CXCL9 and IL-22. These findings provide knee OA patients receiving hypertonic dextrose prolotherapy, which accompanying with the improvement of knee pain, stiffness, and function and increasing tendency in the medial minimum joint space width.

\section{Background}

Knee osteoarthritis $(\mathrm{OA})$ is a common chronic degenerative disease. About $33.6 \%$ of elders over 65 years of age will have knee $\mathrm{OA}$, which is manifested with joint pain, stiffness, and limited range of motion and progressively results in functional impairment $[1,2]$. OA knee as a disease is characterized by joint synovial reaction with articular cartilage and subchondral bone destruction. The choice of clinical treatment options depends on the severity of the knee OA. Non-pharmacological management may include weight loss, therapeutic exercise, electric modality physiotherapy, and use of a knee brace and an insole fit [3-5].

Pharmacological management may include oral analgesics, anti-inflammatory drugs, a glucosamine supplement, and joint injections with corticosteroid at the acute joint effusion stage and a viscosupplementation of hyaluronic acid [6-8]. Surgical intervention with osteotomy or total knee replacement will be considered if medical treatment fails. Prolotherapy, known as a complementary treatment, involves the injection of an irritant solution and hypothetically will induce a local inflammatory reaction, thus facilitating the regeneration of connective tissue [9]. Hypertonic dextrose is the most commonly injected solution, and its efficacy in knee OA has been reported in recent years [10-12]. However, the detailed mechanism is not well elucidated, leading to our interest in the knee joint's synovial membrane and cartilage response to hypertonic dextrose prolotherapy.

Previous studies revealed the protein expression in the synovial fluid underlying the pathogenesis of knee OA [13, 14]. The mechanism of prolotherapy for knee OA needs to be elucidated, especially with respect to the inflammation and regeneration of the related pathway. All cell functions, including cell proliferation, cell death and differentiation, as well as maintenance of health status and disease development, are controlled by many genes and signaling pathways. However, almost all cell functions are executed by proteins, which cannot be studied by DNA and RNA alone. Experimental analysis clearly shows a disparity between the relative expression levels of mRNA and their corresponding proteins [15]. Therefore, it is critical to analyze the protein profile by Human Cytokine Antibody Array. Furthermore, cytokines play an important role in innate immunity, apoptosis, angiogenesis, cell growth and differentiation in most disease processes, including cancer and cardiac diseases [16]. The interaction between cytokines and the cellular immune system is a dynamic process. The interactions of positive and negative stimuli and positive as well as negative regulatory loops are complex and often involve multiple cytokines. Combining cytokine analysis with clinical 
investigation, we conducted a study to provide some molecular evidence involving the hypertonic dextrose prolotherapy of knee OA.

\section{Methods}

\section{Patient recruitment}

In this single-arm study, patients who were over 65 years of age and who had been suffering from at least 6 months of symptomatic knee OA met the clinical criteria of the American Rheumatological Association for moderate or moderate-to-severe knee OA (grade II or III according to the radiological classification of knee OA defined by the Kellgern-Lawrence system) and were recruited from the Physical Medicine and Rehabilitation out-patient service at National Yang-Ming University Hospital in 2016.1.1 2017.6 .30 [17]. The exclusion criteria were patients who had severe knee OA (grade IV), a history of rheumatoid or other inflammatory arthritis, received physiotherapy during the previous one to two weeks prior to the treatment, received oral corticosteroids or anticoagulant, and any knee intra-articular injections during the previous one month prior to the treatment, had poorly controlled diabetes mellitus with fasting blood sugar greater than $200 \mathrm{mg} / \mathrm{dL}$, or a history of knee surgery, dementia or psychological disease. The aim and whole course of the study were explained orally to all 12 patients. Procedural risks were also explained and patients could quit any time. Written informed consents were obtained from all study patients. The study protocol was sent to the Institution Review Board of the Yang-Ming University Hospital and was approved. (IRB No. 2015B004)

\section{Intervention}

Each patient received five intra-articular injections at 2-week intervals in weeks $0,2,4,6$, and 8 . During the procedure, each patient sat on a bed with the knee flexed at 90 degrees, and the injection site was marked at the anteromedial or anterolateral part of the knee. After proper sterilization, $25 \%$ dextrose $6 \mathrm{~mL}$ was injected into the knee joint via the anteromedial or anterolateral approach by an expert physiatrist using a 22-gauge needle [10]. Corticosteroid or NSAID anti-inflammatory drugs were avoided after injections (Fig. 1).

\section{Outcome measurement}

For clinical outcome measurements, we compared the validated Western Ontario McMaster University Osteoarthritis (WOMAC) Index and the standing knee X-ray before the first injection and 2 weeks after the last injection. The WOMAC questionnaire consists of 24-items in three subscales for measuring pain (5 items), joint stiffness (2 items) and physical function (17 items). The answer to each question was scored in 100-mm visual analogue format. Standard standing posterior-anterior view radiographs were taken with the patient's knee joint fully extended. The minimum joint space widths of the respective medial and lateral compartment of the tibia-femoral joint were assessed by the same radiologist using the picture archiving and communication system [18].

\section{Sample correction and preparation}

Each patient was placed in a supine position with the knee flexed at $10 \sim 15$ degrees. Under ultrasound guidance, a sample of about $1 \mathrm{~mL}$ of synovial fluid was aspirated from the suprapatella bursa via the superomedial or superolateral approach before the first injection and 2 weeks after the last injection [19]. The synovial fluid samples were stored at $-30^{\circ} \mathrm{C}$ for further analysis.

\section{Secreted angiogenic profile by cytokine antibody array}

The patients' secretion of inflammatory factors was evaluated in duplicate using a protein array method (RayBio® Human Angiogenesis Antibody Array, RayBiotech C Series 1000, RayBiotech, Inc., Norcross, GA). This assay can simultaneously detect 270 different inflammatory factors (spotted in sub-arrays) with high specificity. The sensitivity of the antibodies in the arrays ranged from 1 to $2000 \mathrm{pg} / \mathrm{mL}$. Each array was incubated with $1.0 \mathrm{~mL}$ of synovial fluid at $4^{\circ} \mathrm{C}$ overnight, and the bound antigens were detected according to the manufacturer's instructions. The membranes were then analyzed according to the manufacturer's instructions, followed by incubation with the sample at $4{ }^{\circ} \mathrm{C}$ overnight and incubation with a biotinylated antibody cocktail with gentle shaking. After another round of washing, membranes were incubated with horseradish peroxidase (HRP)-streptavidin. Finally, signals on the membranes were detected by a chemiluminescent detection system (Bio-Rad, Hercules, CA, USA). To 
determine the relative concentrations of the inflammatory factors in the synovial fluid samples, Quantitative analysis of fluorescence assays was conducted using ImageGauge 3.46 software (Fujifilm, Inc.), as previously described.

\section{Cytokine bead array (CBA)}

The synovial fluid was tested for MMP2, TIMP-1, EGF, IL-10 and IL-22 using a CBA kit from BD, as per the manufacturer's protocol. Concentrations of MMP2, TIMP-1, EGF, IL-10 and IL-22 were measured using a LEGENDplex Human Inflammation Panel CBA (Biolegend). The LEGENDplex CBA was optimized so that each test could be performed using half of the manufacturer's recommended volumes for samples and reagents, and all other aspects of the assay were performed following the manufacturer's instructions. Samples were acquired on a FACSCanto II using FACSDiva software, and analyzed using FlowJo software or LEGENDplex software (Biolegend).

\section{Statistical analysis}

Statistical analysis was carried out with SPSS 13.0 software (SPSS Inc., Chicago, IL, USA). The Wilcoxon signed ranks test was applied to examine the clinical outcome between pre- and post-treatments. The level of two-tailed statistical significance was 0.05. All data are expressed as mean \pm standard error. Student $t$ test (unpaired, 2-tailed) was used for a comparison of continuous data between the experimental groups. Differences in the distribution of the staining score between the groups were assessed using the Mann-Whitney U test. Probability values $(p)$ less than 0.05 were considered as statistically significant.

\section{Results}

\section{WOMAC index and measurement in medial minimum joint space width}

Twelve participants were initially recruited for this study and 2 declined during the treatment period due to intolerable knee pain after injection or an unsatisfactory injection effect and 2 lost follow-up. Finally, a total of 12 knee joints WOMAC index from 12 patients and 10 knee joints $X$ ray medial minimum joint space width were evaluated (Fig. 1).

In Table 1, significant improvements were noted between the pre- and post-treatment groups in the composite and all subscale WOMAC scores (53.2 to 27.0 in WOMAC, 10.3 to 4.8 in WOMAC_A, 4.2 to 2.7 in WOMAC_B, and 38.8 to 19.5 in WOMAC_C, respectively). There was an increasing tendency in the medial minimum joint space width (2.8 to $3.4 \mathrm{~mm}$ ), but no statistically significant difference in the medial and lateral minimum joint space width (Table 1).

Table 1

Clinical evaluation of OA knee with 25\% dextrose treatment in WOMAC index and X ray knee MJS width

\begin{tabular}{|c|c|c|c|c|c|c|c|c|c|c|c|c|}
\hline & \multicolumn{2}{|c|}{ WOMAC (score) } & \multicolumn{2}{|c|}{$\begin{array}{l}\text { WOMAC_A } \\
\text { (score) }\end{array}$} & \multicolumn{2}{|c|}{$\begin{array}{l}\text { WOMAC_B } \\
\text { (score) }\end{array}$} & \multicolumn{2}{|c|}{$\begin{array}{l}\text { WOMAC_C } \\
\text { (score) }\end{array}$} & \multicolumn{2}{|c|}{$\begin{array}{l}\text { medial MJS } \\
(\mathrm{mm})\end{array}$} & \multicolumn{2}{|c|}{$\begin{array}{l}\text { lateral MJS } \\
(\mathrm{mm})\end{array}$} \\
\hline & $\begin{array}{l}\text { mean } \\
\pm S D\end{array}$ & $p$ & $\begin{array}{l}\text { mean } \\
\pm S D\end{array}$ & $p$ & $\begin{array}{l}\text { mean } \\
\pm S D\end{array}$ & $p$ & $\begin{array}{l}\text { mean } \\
\pm S D\end{array}$ & $p$ & $\begin{array}{l}\text { mean } \\
\pm S D\end{array}$ & $p$ & $\begin{array}{l}\text { mean } \\
\pm S D\end{array}$ & $p$ \\
\hline $\begin{array}{l}\text { Pre- } \\
\text { treatment }\end{array}$ & $\begin{array}{l}53.2 \\
\pm 14.7\end{array}$ & \multirow[t]{2}{*}{$0.002^{\#}$} & $\begin{array}{l}10.3 \\
\pm 3.1\end{array}$ & \multirow[t]{2}{*}{$0.004^{\#}$} & $\begin{array}{l}4.2 \pm \\
1.3\end{array}$ & \multirow[t]{2}{*}{$0.011^{\#}$} & $\begin{array}{l}38.8 \\
\pm 10.9\end{array}$ & \multirow[t]{2}{*}{$0.002^{\#}$} & $\begin{array}{l}2.8 \pm \\
1.6\end{array}$ & \multirow[t]{2}{*}{0.059} & $\begin{array}{l}6.7 \pm \\
1.8\end{array}$ & \multirow[t]{2}{*}{0.575} \\
\hline $\begin{array}{l}\text { Post- } \\
\text { treatment }\end{array}$ & $\begin{array}{l}27.0 \\
\pm 11.6\end{array}$ & & $\begin{array}{l}4.8 \pm \\
1.9\end{array}$ & & $\begin{array}{l}2.7 \pm \\
1.8\end{array}$ & & $\begin{array}{l}19.5 \\
\pm 9.0\end{array}$ & & $\begin{array}{l}3.4 \pm \\
1.3\end{array}$ & & $\begin{array}{l}6.7 \pm \\
1.8\end{array}$ & \\
\hline
\end{tabular}

WOMAC: Western Ontario McMaster University Osteoarthritis Index, MJS: minimal joint space; $\mathrm{n}=12$ in WOMAC score and 10 in MJS width;

Wilcoxon Signed Ranks Test, ${ }^{*} p<0.05$

\section{Inflammation-related cytokine biomarker screening}

At last, 8 synovial fluid samples from patients were collected completely. This observation suggested the presence of dextrose intervention in the medial minimum joint space width between the pre- and post-treatment groups. To explore this mechanism of paracrine regulation, the human chemokine and cytokine antibody array (Ray Biotech Inc., Norcross, GA), including 274 specific 
antibodies, was used. Potential biomarkers in the synovial fluid for evaluating cytokines were screened using a cytokine array. Among these candidate cytokines identified, we found that TGF- $\beta 1$, soluble M-CSF, MDC, BMP6, CCL23, CNTF and EGF individually showed a 1.5-fold greater inducible expression than the pretreatment groups in the knee-joint samples compared to the human cytokine antibody array C6 (Fig. 2A), with Flt-3 and MIG showing the decreasing levels by 1.5 -fold. Interestingly, TIMP1 and soluble MIP-1a and TRAIL-R3 synergistically increased the effects of the post-treatment groups from array C7. Importantly, we found that Adipsin, Furin, Galectin 7, MICA, MMP-2, LYVE-1, Maraosin, MICB, GH1, IL10, BCAM, IL-22, MMP-10, Siglec 9, Trappin 2, PAI-1, TREM-1, TSH, VCAM-1 and GDF-15 acted as autocrine factors from array C9. Additionally, we showed that recessively expressed the paracrine modulation of Leptin, ALCAM, CD80, CXCL16, IL-2, MPIF-1 and TIMP-4 from array C8 acting on the post-treatment groups, and other factors, including PSA, CA-XI, AFP and IL-17C, dominantly increased the effects of the post-treatment groups from array $\mathrm{C} 10$. As shown in Fig. 2B, which illustrates the results of the forty-seven differences observed after dextrose intervention, including the upregulation of 37 proteins and the downregulation of 10 proteins, in the post-treatment groups of knee OA patients.

\section{Biomarker verification}

This result indicates that increased concentrations of these cytokines in synovial fluid were associated with the two-week hypertonic dextrose prolotherapy's being useful as biomarkers. Therefore, these cytokines were further examined by quantitative detection. The all samples from synovial fluid from the 12 knee OA patients between the pre- and post-treatment groups, individually assessed was collected, and a cytokine bead array was performed to evaluate the secretion of select cytokines by quantitative analysis. The secretion of pro-inflammatory cytokine matrix metalloproteinase-2 (MMP-2), TIMP metallopeptidase inhibitor 1 (TIMP-1), Epidermal growth factor (EGF), Interleukin-10 (IL-10) and Interleukin-22 (IL-22) were observed to be higher in the post-treatment groups compared to their fresh counterparts (Fig. 3).

\section{Discussion}

Our study showed similarly improved results of WOMAC scales compared to the previous studies reported by Dumais in 2012 , Eslamian in 2015, and Rabago in 2012, 2013 and 2015. For disclosing the cytokine markers of early response to hypertonic dextrose prolotherapy, the follow-up period was 10 weeks post first injection in this study, a shorter period than in previous studies. Nevertheless, the clinical outcomes including pain, joint stiffness and physical function were also improved. This finding indicated that the hypertonic dextrose intra-articular injections for OA knee patients have a clinically effect lasting from weeks to months post treatment $[20,21]$.

Few studies follow the joint space width as an outcome measurement after hypertonic dextrose phototherapy for knee OA. Our study tried to survey the knee-joint cartilage structural change in addition to functional evaluation. Though there was no statistically significant improvement, the medial minimum joint space width increased in most of the knee joints after 5 injections. This result is compatible with the chondrogenic effect of intra-articular hypertonic dextrose in knee OA as published by Topol GA et al. in 2016 [22].

Dextrose prolotherapy is an alternative to surgery for knee osteoarthritis patients. The potential mechanism of dextrose prolotherapy relevant pain-intensity reduction is associated with the hyperpolarization of nociceptive pain fibers by opening the potassium channels [21]. Prolotherapy simulates the normal tissues' healing and repair response, which includes the three stages of inflammation, proliferation, and tissue remodeling [23]. Hypertonic dextrose solutions induce inflammation and stimulate local healing in injured articular tissue through attracting immune cells. In addition, some in vitro and in vivo studies indicated that dextrose also augments the growth of ligaments and tendons, fibroblastic proliferation, and the restoration of the extracellular matrix and articular cartilage by triggering the production of growth factors [20, 24, 25].

The biological mechanisms of dextrose have been indicated in cell and animal models. However, the question of which proteins that participate in tissue repair and the healing process will be regulated by hypertonic dextrose in human knee joints remains ambiguous. Therefore, we used a human cytokine antibody array to evaluate the expression of dextrose-induced cytokine in synovial fluid. A number of immune cells such as macrophages, mast cells, leucocytes, and T cells, which have been found in the synovial tissues of OA patients, are involved in the pathogenesis of OA [26-29]. RAGE, CA11, and GDF-15 control leucocyte

Page 5/12 
adhesion, mast-cell-modulated inflammation, and macrophage activation, respectively [30-32]. IL-22, the proinflammatory cytokine, has been demonstrated to modulate inflammatory processes in inflamed and non-inflamed synovium from osteoarthritis patients [33]. We found that hypertonic dextrose increased many cytokines, such as RAGE, CA11, GDF-15, TREM-1, and IL-22, which contribute to the recruitment of inflammatory cells and inflammation.

The biology of $\mathrm{OA}$ is also influenced by the $\mathrm{T}$ cell-mediated immune response. Both $\mathrm{CD} 4^{+}$and $\mathrm{CD} 8^{+} \mathrm{T}$ cells induce inflammation and cartilage degradation $[29,34,35]$. Regulatory T cells (Treg cells), suppressor T cells, inhibit the proliferation of CD $4^{+}$and $\mathrm{CD}^{+} \mathrm{T}$ cells. The Treg cell response is decreased and is involved in the pathogenesis of OA $[29,36]$. The accumulation of $\mathrm{T}$ cells and the chemoattraction of resting T cells are regulated by cytokines CXCL9,-16, and MPIF-1 [37-39]. Siglec-9 is a critical immunosuppressor that promotes Treg cell differentiation in the pathogenesis of rheumatoid arthritis (RA) [40]. The expected increased inflammation process is induced by hypertonic dextrose. Notably, we found that $10 \%$ dextrose not only diminishes the expression of CXCL16 and MPIF-1 but also increases the level of Siglec-9.

A number of growth factors, such as platelet-derived growth factor (PDGF), epidermal growth factor (EGF), transforming growth factor $\beta$ (TGF- $\beta 1$ ), basic fibroblast growth factor (bFGF), insulin-like growth factor (IGF), and connective tissue growth factor (CTGF), are essential for the growth and repair of ligaments, tendons, and cartilage [24]. TGF- $\beta$ has been shown to trigger cartilage matrix synthesis and chondrogenesis of bone-marrow-derived mesenchymal stem cells (MSCs) and to promote the repair of cartilage defects [41, 42]. BMP-6, a member of the TGF-beta superfamily of cytokines, participates in the maintenance/repair of human articular cartilage [43] EGF, a potent mitogen that augments MSCs and fibroblast proliferation, is involved in the development and healing of tendons and ligaments [44]. Thyroid hormone is the important regulator for remodeling and maintaining bone and cartilage repair. The concentration of thyroid hormone is modulated by the negative feedback regulation of thyrotropin-releasing hormone (TRH) and thyroid-stimulating hormone (TSH) $[45,46]$. Some studies demonstrated that high glucose concentration induces the growth and repair of normal cells and tissues and the production of growth factors and hormones $[24,47]$. The results showed that TGF- $\beta$, EGF and TSH are overexpressed with $10 \%$ dextrose in synovial fluid.

Matrix metalloproteinases (MMPs), a large group of zinc-dependent endopeptidases, have been classified into six groups: collagenases (MMP-1, -8, -13), gelatinases (MMP-2, -9), stromelysins (MMP-3, -10, -11), matrilysins (MMP-7, -26), membrane-type MMPs (MMP-14, -15, 16, -17,-24, -25), and other nonclassified MMPs (MMP-12, -19, 20, -21, -23A/B, -27, -28). MMP-1, -2, -3, -9, and -13 cleave the components of the extracellular matrix (ECM) and serve as critical mediators of cartilage destruction in $O A$ $[48,49]$. The activities of MMPs are downregulated with tissue inhibitors of metalloproteinases (TIMP-1, TIMP-2, TIMP-3, and TIMP-4) [50]. MMP-1, -3, -9, and - 13-triggered degradation of ECM are suppressed with TIMP-1 [51]. Furin, proprotein convertase, has been shown to reduce MMP-13 expression in a TGF $\beta$-dependent manner and to restrict osteoarthritis in mice [52]. Besides MMPs, serine proteases also degrade ECM and contribute to articular cartilage destruction in OA. Trappin-2, a small serine protease inhibitor, was found to bind to ECM, resulting in the inhibition of serine protease-mediated degradation of ECM [53, 54]. PAI-1, a serine protease inhibitor, suppresses the degradation of ECM and inhibits osteoclastic bone resorption and subchondral osteopenia after the induction of OA $[55,56]$. We found that $10 \%$ dextrose enhanced MMP-2 expression, and the protein levels of TIMP-1, EGF, IL-10, and IL-22 were increased in synovial fluid.

Post-injection soreness is common in hypertonic dextrose prolotherapy [57]. During this treatment course, patients needed to receive 5 injections, and most of them felt short-term discomfort after each injection. Those factors decreased the willingness of the elderly with knee OA to participate in this research project. This may mean that the clinical application of this treatment protocol is not acceptable for every patient. Although the hypertonic dextrose prolotherapy is effective, multiple injections and post-injection discomfort are still clinical issues that may lessen patient compliance. This was the reason for our interest, and why we tried to explore the key cytokines related to effective and side-effect mechanisms. For wide clinical application, further studies need to be designed.

\section{Abbreviations}


OA: Osteoarthritis; WOMAC: Western Ontario McMaster University Osteoarthritis; MMP-2: Metalloproteinase-2; TIMP-1: TIMP metallopeptidase inhibitor 1; EGF: Epidermal growth factor; IL-10: Interleukin-10; IL-22: Interleukin-22; T cells: Treg cells; PDGF: Platelet-derived growth factor; EGF: Epidermal growth factor; TGF-b1: Transforming growth factor b; bFGF: Basic fibroblast growth factor; IGF: Insulin-like growth factor; CTGF: Connective tissue growth factor; MSCs: Mesenchymal stem cells; TRH: thyrotropin-releasing hormone; TSH: Thyroid-stimulating hormone; MMPs: Matrix metalloproteinases; ECM: Extracellular matrix

\section{Declarations}

\section{Acknowledgments}

The Funding for this study were provided in part by research grants from National Yang-Ming University Hospital (RD2016-018) and supported by grants BMRPD42, CMRPF6J0081, CMRPF6K0071 from Chang Gung Memorial Hospital, Chiayi, Taiwan, and Chang Gung University of Science and Technology, Chia-Yi Campus, Taiwan.

\section{Conflict of interest}

The authors have declared that no competing interests exist. All other authors declare no competing interests. This publication has been no significant financial support for this work that could have influenced its outcome.

\section{Consent for publication}

Not applicable.

\section{Authors' contributions}

PJP: Conception, Research design, Collection, assembly of data, Performed the experiments, Interpretation of data and manuscript writing. JCW: Collection, assembly of data, and performed the experiments. CCT: Interpretation of data. HCK: Conception, Performed the experiments, Interpretation of data and manuscript writing and final approval of manuscript. All authors read and approved the final manuscript.

\section{References}

1. Lawrence RC, Felson DT, Helmick CG, Arnold LM, Choi H, Deyo RA, et al. Estimates of the prevalence of arthritis and other rheumatic conditions in the United States. Part II. Arthritis Rheum. 2008;58(1):26-35.

2. Felson DT. Clinical practice. Osteoarthritis of the knee. N Engl J Med. 2006;354(8):841-8.

3. Jones RK, Chapman GJ, Parkes MJ, Forsythe L, Felson DT. The effect of different types of insoles or shoe modifications on medial loading of the knee in persons with medial knee osteoarthritis: a randomised trial. J Orthop Res. 2015;33(11):164654.

4. Maly MR, Robbins SM. Osteoarthritis year in review 2014: rehabilitation and outcomes. Osteoarthritis Cartilage. 2014;22(12):1958-88.

5. Hawker GA, Mian S, Bednis K, Stanaitis I. Osteoarthritis year 2010 in review: non-pharmacologic therapy. Osteoarthritis Cartilage. 2011;19(4):366-74.

6. McAlindon TE, Bannuru RR, Sullivan MC, Arden NK, Berenbaum F, Bierma-Zeinstra SM, et al. OARSI guidelines for the nonsurgical management of knee osteoarthritis. Osteoarthritis Cartilage. 2014;22(3):363-88.

7. Trigkilidas D, Anand A. The effectiveness of hyaluronic acid intra-articular injections in managing osteoarthritic knee pain. Ann R Coll Surg Engl. 2013;95(8):545-51.

8. Hunter DJ, Felson DT. Osteoarthritis. BMJ. 2006;332(7542):639-42.

9. Distel LM, Best TM. Prolotherapy: a clinical review of its role in treating chronic musculoskeletal pain. PM R. 2011;3(6 Suppl 1):78-81. 
10. Eslamian F, Amouzandeh B. Therapeutic effects of prolotherapy with intra-articular dextrose injection in patients with moderate knee osteoarthritis: a single-arm study with 6 months follow up. Ther Adv Musculoskelet Dis. 2015;7(2):35-44.

11. Rabago D, Mundt M, Zgierska A, Grettie J. Hypertonic dextrose injection (prolotherapy) for knee osteoarthritis: Long term outcomes. Complement Ther Med. 2015;3(3):388-95.

12. Rabago D, Patterson JJ, Mundt M, Kijowski R, Grettie J, Segal NA, et al. Dextrose prolotherapy for knee osteoarthritis: a randomized controlled trial. Ann Fam Med. 2013;11(3):229-37.

13. Liao W, Li Z, Wang H, Wang J, Fu Y, Bai X. Proteomic analysis of synovial fluid: insight into the pathogenesis of knee osteoarthritis. Int Orthop. 2013;37(6):1045-53.

14. Ritter SY, Subbaiah R, Bebek G, Crish J, Scanzello CR, Krastins B, et al. Proteomic analysis of synovial fluid from the osteoarthritic knee: comparison with transcriptome analyses of joint tissues. Arthritis Rheum. 2013;65(4):981-92.

15. Oh HS, Moharita A, Potian JG, Whitehead IP, Livingston JC, Castro TA, et al. Bone marrow stroma influences transforming growth factor-beta production in breast cancer cells to regulate c-myc activation of the preprotachykinin-I gene in breast cancer cells. Cancer Res. 2004;64(17):6327-36.

16. Potian JA, Aviv H, Ponzio NM, Harrison JS, Rameshwar P. Veto-like activity of mesenchymal stem cells: functional discrimination between cellular responses to alloantigens and recall antigens. J Immunol. 2003;171(7):3426-34.

17. Altman RD. Criteria for classification of clinical osteoarthritis. J Rheumatol Suppl. 1991;27:10-2.

18. Bruyere O, Henrotin YE, Honore A, Rovati LC, Seidel L, Dardenne C, et al. Impact of the joint space width measurement method on the design of knee osteoarthritis studies. Aging Clin Exp Res. 2003;15(2):136-41.

19. Douglas RJ. Aspiration and injection of the knee joint: approach portal. Knee Surg Relat Res. 2014;26(1):1-6.

20. Sit RW, Chung V, Reeves KD, Rabago D, Chan KK, Chan DC, et al. Hypertonic dextrose injections (prolotherapy) in the treatment of symptomatic knee osteoarthritis: A systematic review and meta-analysis. Sci Rep. 2016;6:25247.

21. Hassan F, Trebinjac S, Murrell WD, Maffulli N. The effectiveness of prolotherapy in treating knee osteoarthritis in adults: a systematic review. Br Med Bull. 2017;122(1):91-108.

22. Topol GA, Podesta LA, Reeves KD, Giraldo MM, Johnson LL, Grasso R, et al. Chondrogenic Effect of Intra-articular HypertonicDextrose (Prolotherapy) in Severe Knee Osteoarthritis. PM R. 2016;8(11):1072-82.

23. Steilen D, Hauser R, Woldin B, Sawyer S. Chronic neck pain: making the connection between capsular ligament laxity and cervical instability. Open Orthop J. 2014;8:326-45.

24. Hauser RA, Lackner JB, Steilen-Matias D, Harris DK. A Systematic Review of Dextrose Prolotherapy for Chronic Musculoskeletal Pain. Clin Med Insights Arthritis Musculoskelet Disord. 2016;9:139-59.

25. Pugliese G, Pricci F, Locuratolo N, Romeo G, Romano G, Giannini S, et al. Increased activity of the insulin-like growth factor system in mesangial cells cultured in high glucose conditions. Relation to glucose-enhanced extracellular matrix production. Diabetologia. 1996;39(7):775-84.

26. Bondeson J, Wainwright SD, Lauder S, Amos N, Hughes CE. The role of synovial macrophages and macrophage-produced cytokines in driving aggrecanases, matrix metalloproteinases, and other destructive and inflammatory responses in osteoarthritis. Arthritis Res Ther. 2006;8(6):R187.

27. de Lange-Brokaar BJ, Kloppenburg M, Andersen SN, Dorjee AL, Yusuf E, Herb-van Toorn L, et al. Characterization of synovial mast cells in knee osteoarthritis: association with clinical parameters. Osteoarthritis Cartilage. 2016;24(4):664-71.

28. Koch AE, Burrows JC, Haines GK, Carlos TM, Harlan JM, Leibovich SJ. Immunolocalization of endothelial and leukocyte adhesion molecules in human rheumatoid and osteoarthritic synovial tissues. Lab Invest. 1991;64(3):313-20.

29. Li YS, Luo W, Zhu SA, Lei GH. T Cells in Osteoarthritis: Alterations and Beyond. Front Immunol. 2017;8:356.

30. Chavakis T, Bierhaus A, Nawroth PP. RAGE (receptor for advanced glycation end products): a central player in the inflammatory response. Microbes Infect. 2004;6(13):1219-25.

31. Henry EK, Sy CB, Inclan-Rico JM, Espinosa V, Ghanny SS, Dwyer DF, et al. Carbonic anhydrase enzymes regulate mast cellmediated inflammation. J Exp Med. 2016;213(9):1663-73. 
32. Tanrikulu O, Sariyildiz MA, Batmaz I, Yazmalar L, Polat N, Kaplan I, et al. Serum GDF-15 level in rheumatoid arthritis: relationship with disease activity and subclinical atherosclerosis. Acta Reumatol Port. 2017;42(1):66-72.

33. Deligne C, Casulli S, Pigenet A, Bougault C, Campillo-Gimenez L, Nourissat G, et al. Differential expression of interleukin-17 and interleukin-22 in inflamed and non-inflamed synovium from osteoarthritis patients. Osteoarthritis Cartilage. 2015;23(11):1843-52.

34. Shen PC, Wu CL, Jou IM, Lee CH, Juan HY, Lee PJ, et al. T helper cells promote disease progression of osteoarthritis by inducing macrophage inflammatory protein-1 gamma. Osteoarthritis Cartilage. 2011;19(6):728-36.

35. Apinun J, Sengprasert P, Yuktanandana P, Ngarmukos S, Tanavalee A, Reantragoon R. Immune Mediators in Osteoarthritis: Infrapatellar Fat Pad-Infiltrating CD8 + T Cells Are Increased in Osteoarthritic Patients with Higher Clinical Radiographic Grading. Int J Rheumatol. 2016;2016:9525724.

36. Sakaguchi S, Wing K, Onishi Y, Prieto-Martin P, Yamaguchi T. Regulatory T cells: how do they suppress immune responses? Int Immunol. 2009;21(10):1105-11.

37. Ochiai E, Sa Q, Brogli M, Kudo T, Wang X, Dubey JP, et al. CXCL9 is important for recruiting immune T cells into the brain and inducing an accumulation of the $T$ cells to the areas of tachyzoite proliferation to prevent reactivation of chronic cerebral infection with Toxoplasma gondii. Am J Pathol. 2015;185(2):314-24.

38. Nanki T, Shimaoka T, Hayashida K, Taniguchi K, Yonehara S, Miyasaka N. Pathogenic role of the CXCL16-CXCR6 pathway in rheumatoid arthritis. Arthritis Rheum. 2005;52(10):3004-14.

39. Dhir V, Sandhu A, Gupta N, Dhawan V, Sharma S, Sharma A. Low serum levels of myeloid progenitor inhibitory factor-1 predict good response to methotrexate in rheumatoid arthritis. ISRN Inflamm. 2013;2013:460469.

40. Wang X, Liu D, Ning Y, Liu J, Wang X, Tu R, et al. Siglec-9 is upregulated in rheumatoid arthritis and suppresses collageninduced arthritis through reciprocal regulation of Th17-/Treg-cell differentiation. Scand J Immunol. 2017;85(6):433-40.

41. Civinini R, Nistri L, Martini C, Redl B, Ristori G, Innocenti M. Growth factors in the treatment of early osteoarthritis. Clin Cases Miner Bone Metab. 2013;10(1):26-9.

42. Diao H, Wang J, Shen $\mathrm{C}$, Xia S, Guo T, Dong L, et al. Improved cartilage regeneration utilizing mesenchymal stem cells in TGF-beta1 gene-activated scaffolds. Tissue Eng Part A. 2009;15(9):2687-98.

43. Bobacz K, Gruber R, Soleiman A, Erlacher L, Smolen JS, Graninger WB. Expression of bone morphogenetic protein 6 in healthy and osteoarthritic human articular chondrocytes and stimulation of matrix synthesis in vitro. Arthritis Rheum. 2003;48(9):2501-8.

44. Goncalves Al, Rodrigues MT, Lee SJ, Atala A, Yoo JJ, Reis RL, et al. Understanding the role of growth factors in modulating stem cell tenogenesis. PLoS One. 2013;8(12):e83734.

45. Hellevik Al, Johnsen MB, Langhammer A, Fenstad AM, Furnes O, Storheim K, et al. Incidence of total hip or knee replacement due to osteoarthritis in relation to thyroid function: a prospective cohort study (The Nord-Trondelag Health Study). BMC Musculoskelet Disord. 2017;18(1):201.

46. Williams GR. Thyroid hormone actions in cartilage and bone. Eur Thyroid J. 2013;2(1):3-13.

47. Hashemi M, Jalili P, Mennati S, Koosha A, Rohanifar R, Madadi F, et al. The Effects of Prolotherapy With Hypertonic Dextrose Versus Prolozone (Intraarticular Ozone) in Patients With Knee Osteoarthritis. Anesth Pain Med. 2015;5(5):e27585.

48. Jablonska-Trypuc A, Matejczyk M, Rosochacki S. Matrix metalloproteinases (MMPs), the main extracellular matrix (ECM) enzymes in collagen degradation, as a target for anticancer drugs. J Enzyme Inhib Med Chem. 2016;31(sup1):177-83.

49. Burrage PS, Mix KS, Brinckerhoff CE. Matrix metalloproteinases: role in arthritis. Front Biosci. 2006;11:529-43.

50. Yoshihara Y, Nakamura H, Obata K, Yamada H, Hayakawa T, Fujikawa K, et al. Matrix metalloproteinases and tissue inhibitors of metalloproteinases in synovial fluids from patients with rheumatoid arthritis or osteoarthritis. Ann Rheum Dis. 2000;59(6):455-61.

51. Chevalier X, Conrozier T, Gehrmann M, Claudepierre P, Mathieu P, Unger S, et al. Tissue inhibitor of metalloprotease-1 (TIMP1) serum level may predict progression of hip osteoarthritis. Osteoarthritis Cartilage. 2001;9(4):300-7.

52. Lin H, Hay E, Latourte A, Funck-Brentano T, Bouaziz W, Ea HK, et al. Proprotein convertase furin inhibits matrix metalloproteinase 13 in a TGFbeta-dependent manner and limits osteoarthritis in mice. Sci Rep. 2018;8(1):10488. 
53. Lu P, Takai K, Weaver VM, Werb Z. Extracellular matrix degradation and remodeling in development and disease. Cold Spring Harb Perspect Biol. 2011;3(12).

54. Jaovisidha K, Etim A, Yamakawa K, Masuda I, Gohr CM, Wakim BT, et al. The serine protease inhibitor trappin-2 is present in cartilage and synovial fluid in osteoarthritis. J Rheumatol. 2006;33(2):318-25.

55. Lee HB, Ha H. Plasminogen activator inhibitor-1 and diabetic nephropathy. Nephrology (Carlton). 2005;10 Suppl:S11-3.

56. Moritake A, Kawao N, Okada K, Tatsumi K, Ishida M, Okumoto K, et al. Plasminogen activator inhibitor-1 deficiency enhances subchondral osteopenia after induction of osteoarthritis in mice. BMC Musculoskelet Disord. 2017;18(1):392.

57. Reeves KD, Sit RW, Rabago DP. Dextrose Prolotherapy: A Narrative Review of Basic Science, Clinical Research, and Best Treatment Recommendations. Phys Med Rehabil Clin N Am. 2016;27(4):783-823.

\section{Figures}

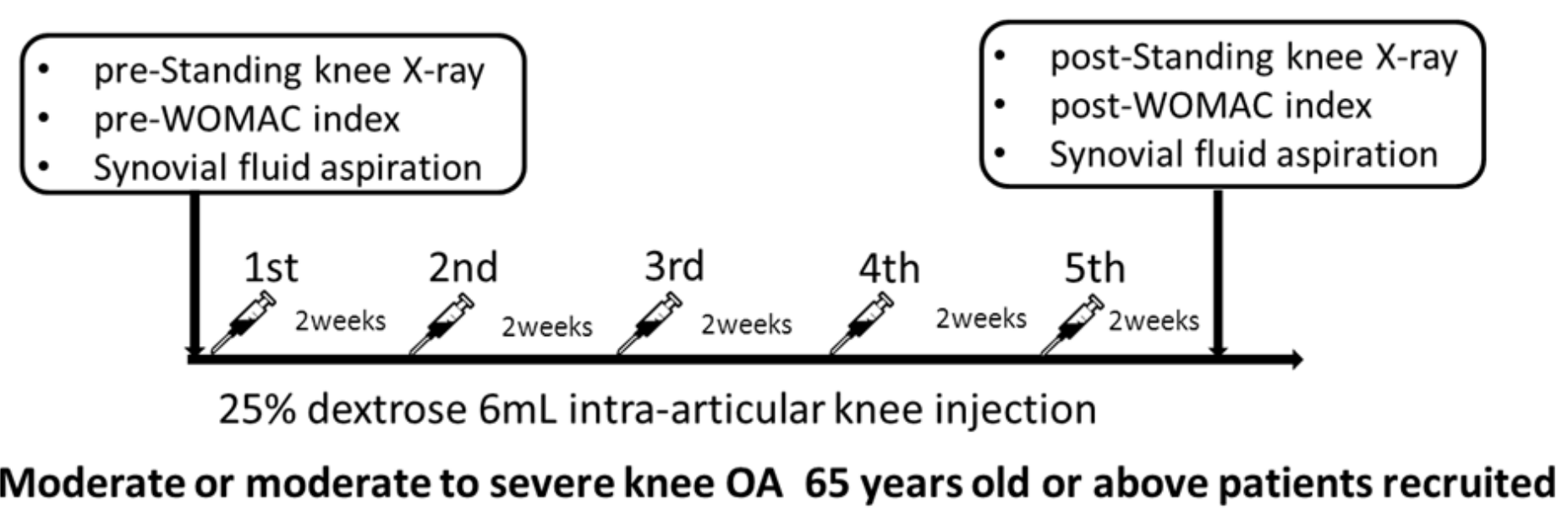

Figure 1

Evaluation protocol of hypertonic dextrose prolotherapy in knee osteoarthritis patients 


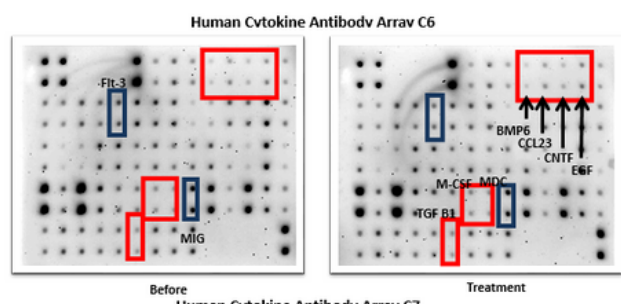

Figure. 2B Human cytokine expression profile
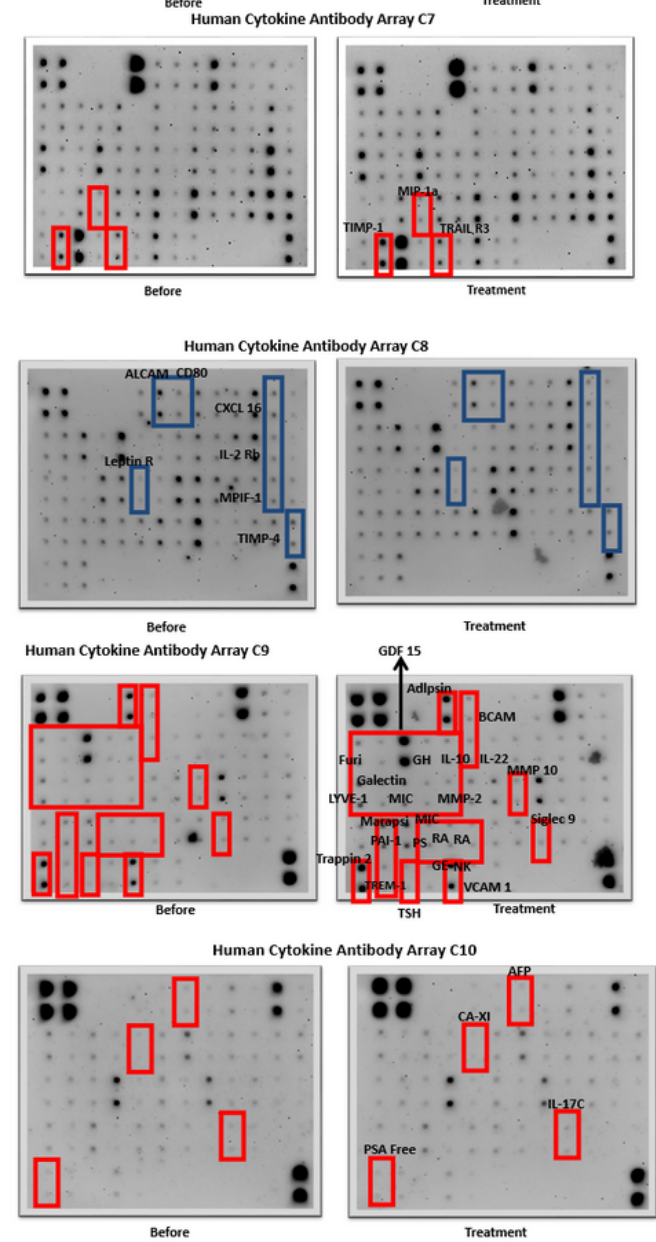

Figure 2

Cytokine antibody array and treatment of knee osteoarthritis (OA). Human 274 cytokines were blotted onto a membrane and arrayed three times following the manufacturer's protocol. The intensities of the relative expression levels of cytokines were quantified by densitometry (VersaDoc imaging system, Bio-Rad). The density value of each test sample was normalized to as described from Human Cytokine Antibody Array C6, C7, C8, C9, C10 (A) and graphed (B). Antibody arrays were used to examine the growth factors secreted by CAFs or the CLS1 cells cultured with or without CAFs in serum-free RPMI medium for $24 \mathrm{~h}$. The arrays were scanned and quantified, and the levels were normalized to those of the positive controls. 
MMP2

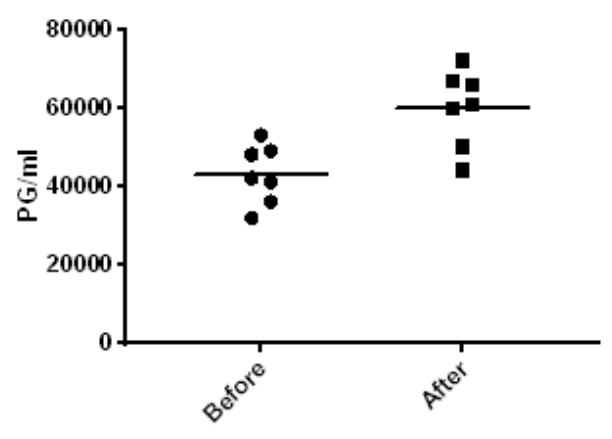

CXCL9

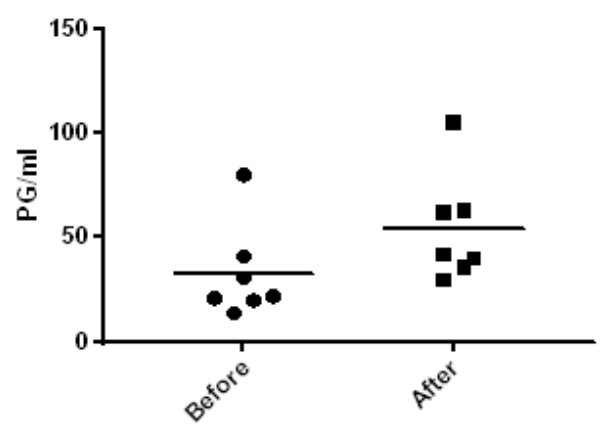

TIMP-1

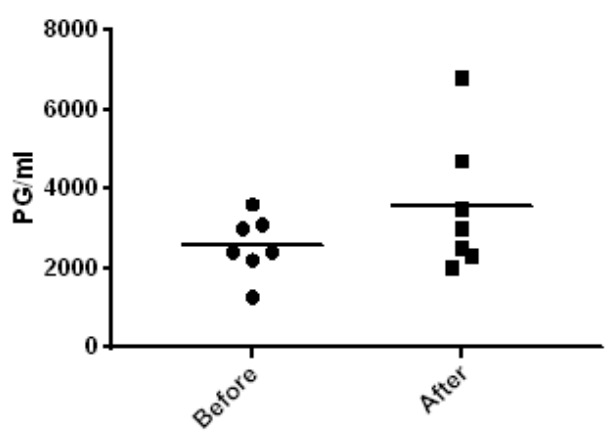

IL22

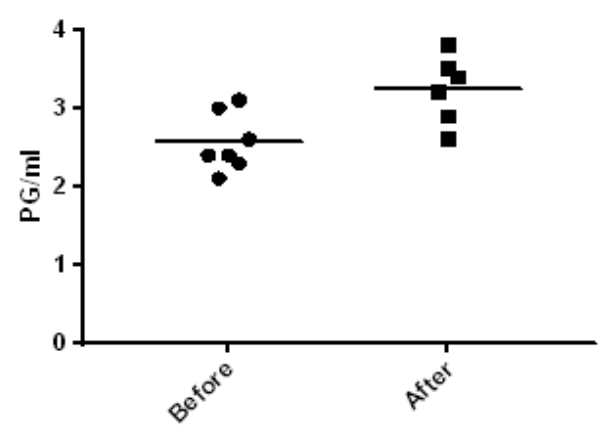

EGF

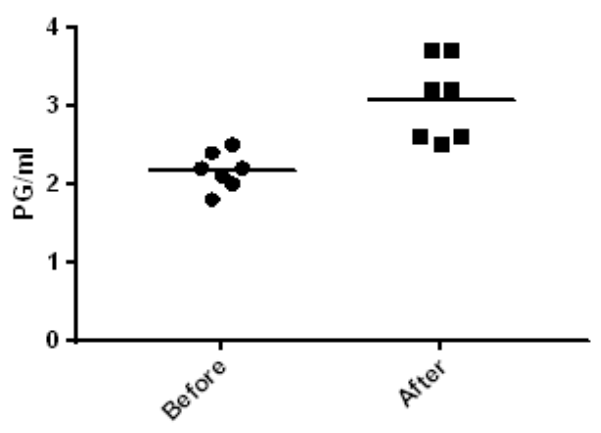

\section{Figure 3}

High glucose treatment of knee osteoarthritis (OA) induce up-regulation of MMP2, TIMP-1, EGF, IL-10 and IL-22 on plasma. Data shown as individual values, $n=12$ synovial fluid, from the 12 knee OA patients was collected * $p<0.05$, comparing parent to pretreatment. 